\title{
O design na cultura tradicional: ênfases e lacunas
}

\section{The design into the traditional culture: emphasis and research gaps}

\author{
ALVES, Milena Carneiro \\ Universidade Federal do Paraná - UFPR | mcarneiroalves@gmail.com \\ SANTOS, Aguinaldo dos \\ Universidade Federal do Paraná - UFPR | asantos@ufpr.br
}

\begin{abstract}
Resumo
A identidade territorial indígena é um campo que precisa ser preservado. Estudar e compreender o comportamento desses povos ajuda o designer a projetar produtos e serviços que agreguem valor ao artesanato, fortaleça sua identidade e que permitam uma melhor comunicação dos indígenas com a sociedade sem interferir na sua cultura ou no seu fazer tradicional. Esta pesquisa utiliza uma Revisão Bibliográfica Sistemática e Assistemática no intuito de entender a relação entre Design de Serviços e Artesanato Indígena. Como resultado, foram identificados os modos de consumo do artesanato indígena, o acesso que o designer possui nessas comunidades tradicionais, o desejo que esses nativos possuem de propagar a sua cultura para além do seu território e as lacunas existentes sobre o tema. A consideração dessas lacunas potencializa a criação de soluções que ampliem o valor econômico gerado pelo artesanato indígena e que propaguem a sua

\section{Abstract}

The indigenous territorial identity is a field that needs to be preserved. By studying and understanding these people behavior, designers become able to design services and products that adds value to the handicraft, strengthen their identity, and allow a better communication of the natives with the society without interfering in their culture. This research uses a Systematic and Unsystematic Bibliographic Review in order to understand the relationship between Service Design and Indigenous Handicrafts. As results, we identified the means of consumption of indigenous handcraft, the designer's access to indigenous communities, the desire of these natives to propagate their culture beyond their territory, and existing gaps in the subject. Taking such gaps into consideration promotes the designing of solutions to expand the economic value of indigenous handcraft and propagate their culture in a co-creative manner, including the concern with sustainable consumption.
\end{abstract} cultura de forma co-criativa, sempre se preocupando com o consumo sustentável.

Palavras-chave: Design de serviços. População indígena. Artesanato. Sistema Produto + Serviço.

Keywords: Service design. Indigenous population. Handcraft. Product service system. 


\section{INTRODUC̣ÃO}

A busca por uma economia mais distribuída é um dos anátemas que pautam o Design Contemporâneo. Economia distribuída é entendida aqui como aquela orientada à produção de base local, por atores de pequeno porte que podem inclusive ser o próprio consumidor. Esta visão está alinhada com o crescente volume de iniciativas voltadas à inclusão social, à promoção da produção e consumo mais sustentável e à valorização da cultura local. Krucken (2009) aponta a necessidade de compreender o contexto local (terroir-território-comportamentos) na busca por soluções efetivamente mais sustentáveis. Entender a cultura e os recursos de um dado território é, contudo, uma atividade complexa posto que envolve um grande número de variáveis nas dimensões físicas e cognitivas. A autora também identifica o designer como um agente capaz de intermediar o conhecimento sobre a produção e o consumo de base local, tradição e inovação no âmbito do território, qualidade local e relações globais.

A busca por uma economia distribuída pode, desta forma, contribuir de forma direta para grupos que na economia centralizada são muitas vezes marginalizados. Dentre estes grupos destacam-se os índios, que no Paraná representam quatro mil indivíduos (CONRADE, 2015). A cultura indígena constitui um dos ícones mais fortes associadas à cultura e a imagem do Brasil (RODRIGUES, 2006). Assim, estudar e compreender o comportamento desses nativos pode ajudar o profissional Designer a projetar produtos e serviços que efetivamente contribuam com esta população em todas as dimensões da sustentabilidade (ambiental, social e econômica).

Dentre os profissionais que podem contribuir para a redução da marginalização da população indígena próxima a espaços urbanos o Designer ocupa posição de destaque. Suas características, em tese, o habilitam para ser um mediador entre a esfera da produção artesanal e o mercado. Para que tal contribuição se efetive é importante que este profissional esteja no meio do processo de desenvolvimento de soluções, mediando a interlocução entre os vários stakeholders. Tal mediação busca ajudar a entender melhor a linguagem terroir, suas condições culturais, econômicas e sociais antes de projetar um novo serviço (NORONHA, 2015).

Os Guaranis são da matriz cultural Tupi e são divididos em três grupos linguísticos: Mbya, Nhandeva e Kaiowá. No presente artigo tratou-se de uma pesquisa realizada a um grupo Mbya, localizado no litoral do Paraná. Nogueira (2005) aponta que a fixação de aldeias Mbya no litoral é uma característica própria da nação Guarani, que busca terras que permitam cultivar suas tradições sem interferências de outras culturas. 
De maneira convencional um dos mecanismos de propagação da cultura indígena e da garantia de sua subsistência econômica na periferia das zonas urbanas é a produção e comercialização de artefatos (artesanato). Sua produção não se dá somente para questões econômicas, mas também como uma narrativa cultural onde simples adornos e cestos contam histórias, mitos e tradições. Segundo Rodrigues (2006), os objetos desse grupo indígena guardam um valor que transita entre beleza e sentido, e são formas sensíveis que expressam sua estrutura social, relação com a natureza e construção da identidade de cada artesão.

A contribuição do artesanato para a propagação da cultura indígena e para a própria subsistência econômica tem se mostrado deficiente. Cavalcante (2014) comenta sobre a preocupação por parte desses povos tradicionais de desenvolver novas formas de preservação e valorização dos seus territórios e conhecimentos, dentro e fora das aldeias. Segundo Carneiro Filho e Souza (2009), a Constituição Federal consagrou aos índios o direito da sua terra, assim, é dever do poder público, por meio da Fundação Nacional do Índio (Funai), assegurar valor e proteção contra a ocupação de terceiros.

Além disto, a ênfase tão somente na comercialização de artefatos físicos é um paradoxo ao se relacionar com a própria preocupação em respeito à preservação da natureza nos agrupamentos indígenas próximos às zonas urbanas, o que tem repercutido em tensões com organizações de proteção ambiental. Como o exemplo, Carneiro Filho e Souza (2009) abordam em seu atlas sobre o roubo de madeiras, surgimento de garimpos e apropriação ilegal de terras na Amazônia, frisando que apenas a população indígena deve usufruir desse território ambiental. Desta forma, entende-se como premente a busca por soluções mais desmaterializadas na promoção da cultura e na geração de renda para esta população. Um das estratégias possíveis para alcançar este objetivo é o Design de Serviços associados à cultura indígena, vinculados ou não aos artefatos produzidos pelos mesmos.

Este artigo investiga este tema, relatando uma Revisão Bibliográfica Sistemática, seguida de uma Revisão Bibliográfica Assistemática com o objetivo de mapear, selecionar e analisar os conceitos e atividades importantes na relação Design de Serviços e Cultura Indígena. Assim, serão observados conceitos de Sistema Produto + Serviço (PSS), Design de Serviços, Identidade e Cultura, e Serviços, com ênfase particular em iniciativas identificadas em outros países, pretendendo responder a pergunta: "Quais são as ênfases e lacunas da relação entre Design de Serviços e Artesanato Indígena no Brasil?". 


\section{MÉTODO}

\section{1 Revisão Bibliográfica Sistemática}

A Revisão Bibliográfica Sistemática (RBS) teve como objetivo mapear, selecionar e analisar os conceitos e atividades importantes na relação entre Design e Artesanato Indígena no Brasil. Por meio desta RBS busca-se identificar as possíveis lacunas existentes seguindo as etapas baseadas na proposta de Conforto, Amaral e Silva (2011).

\subsubsection{Protocolo utilizado}

A Entrada (como é a denominada a primeira fase por Conforto, Amaral e Silva (2011)), houve o entendimento teórico sobre a RBS e o estudo preliminar sobre o assunto com o objetivo de definir o problema do artigo com as seguintes questões: Há contribuição do Design no artesanato indígena brasileiro? Se há essa contribuição, quais são as ênfases e lacunas dessa relação?

Em seguida, com base na identificação da questão da pesquisa, foram definidas as 05 strings de busca identificadas no estudo preliminar do assunto, que estão descritas na figura 01 . As strings de busca são palavras chave, que quando agrupadas, deixam os resultados mais concisos. Os critérios de inclusão definidos foram "Somente no Brasil" e "artigos revisados por pares" (no Portal de Periódicos da Capes).

Os procedimentos adotados foram: Elaboração do protocolo; Escolha das bases de dados; Pesquisa nas bases de dados escolhidas; Seleção de artigos/dissertações/teses após a aplicação de filtros preliminares; Leitura completa dos artigos; Fichamento dos artigos/dissertações/teses relevantes; e Saída (CONFORTO; AMARAL; SILVA, 2011).

\subsection{Revisão Bibliográfica Assistemática}

A Revisão Bibliográfica Assistemática (RBA) buscou identificar aspectos importantes que complementam o que não foi abordado na RBS a fim de proporcionar familiaridade com todos os conceitos estudados. Desta forma, foram feitas pesquisas em livros, artigos, teses, dissertações e um benchmarking (MARSALIA NETO et al., 2008) sobre serviços voltados à cultura indígena em outros países, a fim de apontar eventuais lacunas existentes. 


\section{RESULTADOS}

\subsection{Resultados da Revisão Bibliográfica Sistemática}

\subsubsection{Strings de busca}

A Figura 1 apresenta a quantidade de artigos encontrados pelos sistemas de busca do Portal de Periódico Capes, BDTD e SCOPUS de acordo com as strings de busca. Foram um total de 270 resultados, mas quando filtrados de acordo com os critérios de busca, resultaram em 14 resultados relevantes.

Figura 1 - Strings de Busca.

\begin{tabular}{|c|c|c|c|c|c|c|c|c|}
\hline STRINGS & PORTAIS & QTD & FILTRO 01 & QTD & FILTRO 02 & QTD & FILTRO 03 & QTD \\
\hline "indígena" AND "artesanato" & BDTD & 04 & Título & 02 & Introduçăo & 01 & Introduçăo/Conclusăo & 0 \\
\hline AND"design de serviços" & Periódicos Capes & 07 & Revisado por pares & 04 & Resumo & 04 & Introdução/Conclusão & 01 \\
\hline $\begin{array}{l}\text { "design" AND "brasil" } \\
\text { AND "valorização cultural" }\end{array}$ & Periódicos Capes & 16 & Revisado por pares & 51 & Titulo/Resumo & 04 & Introduçăo/Conclusão & 02 \\
\hline "design" AND & BDTD & 05 & Título & 03 & Resumo & 08 & Introduçăo/Conclusão & 08 \\
\hline "indigena"AND "brasil" & Periódicos Capes & 180 & Revisado por pares & 88 & Título/Resumo & 51 & Introduçāo/Conclusāo & 03 \\
\hline $\begin{array}{c}\text { "design" AND } \\
\text { "indigenous" AND "brazil" }\end{array}$ & Scopus & 54 & Título & 44 & Resumo & 01 & Introdução/Conclusão & 0 \\
\hline $\begin{array}{l}\text { "design" AND"indigenous" } \\
\text { AND "brazil" AND "culture" }\end{array}$ & Scopus & 04 & Título & 0 & & & & \\
\hline
\end{tabular}

Fonte: Autores (2018).

Foram totalizados 08 dissertações/teses no BDTD, 06 artigos no Portal de Periódicos da Capes e apenas 01 no SCOPUS para serem lidos por inteiro.

Nunes (2013), em sua pesquisa exploratória descritiva, realizou um breve estudo sobre as principais ações de design em comunidades brasileiras usando métodos qualitativos e balizados pela antropologia por meio de visitas, entrevistas, observação participante e gravações. Sua análise crítica e comparativa foi baseada em um estudo de caso na comunidade Mumbuca (remanescente quilombola e com heranças indígenas), no Tocantins, com o objetivo de valorizar o seu artesanato.

Como resultado da pesquisa de campo, Nunes (2013) relata que a comunidade mostrou-se acessível ao design apesar da dificuldade de comunicação com eles e os órgãos que os patrocinavam. O autor considera a importância dos artesãos como os sujeitos ativos, com mentes criativas, nos processos desenvolvidos no seu território. Propõe que um dos papéis do designer é trabalhar em conjunto com esses artesãos, visando identificar oportunidades e propor soluções que ajudem a estabelecer parcerias que permitam o desenvolvimento do artesanato dentro do mercado global difundindo a sua tradição e identidade cultural. Além disso, Nunes (2013) comenta que as relações que o design estabelece com a cultura e sociedade aumenta o conhecimento das tradições locais por meio do reconhecimento do 
valor da identidade cultural do artesanato e faz com que o Designer desenvolva produtos com valores comerciais agregados que possuem os valores culturais intrínsecos.

\subsection{2 Ênfases na produção de artefatos físicos nas iniciativas de Design orientadas a Comunidades Indígenas}

A RBS confirmou o pressuposto que a contribuição dos Designers tem sido, via de regra, orientada à produção de artefatos físicos, nos seus 19 resultados considerados relevantes. Nunes (2013), por exemplo, defende que na promoção da cultura indígena se desenvolvam produtos com valores culturais que agreguem valor comercial, com um viés claramente orientado à manufatura de artefatos físicos.

Rodrigues (2006), em estudo de caso que durou dois anos e meio, refletiu sobre o relacionamento do designer com a iconografia indígena, abordando as formas como se operam os cruzamentos dos sistemas estéticos hegemônicos com os estéticos populares (indígenas) e como cada um se apropria das características do outro. O seu foco foi na ornamentação corporal dos índios Kayapó (Amazônia), que se destaca por sua relevante expressão estética, de estrutura social, relação com a natureza e construção de identidade.

Como resultado, comenta que parte da produção indígena é voltada para venda, pois a maioria dessas comunidades tem consciência do interesse e da demanda que sua cultura desperta na população nacional e internacional. Relata a necessidade do designer em se posicionar de uma forma mais consciente e criativa das riquezas culturais; e de assumir responsabilidades de tornar seus produtos mais adaptados ao mercado local sem intervir no fazer tradicional, embora esse último ainda seja questionada a capacidade e legitimidade que o designer tem para realizar essa intervenção (RODRIGUES, 2006).

Cavalcante(2014) realizou uma pesquisa qualitativa com procedimentos metodológicos baseados em estudos etnográficos e iconográficos realizados com observações, entrevistas, oficinas e levantamentos de imagens. E propôs uma revitalização dos conhecimentos indígenas, considerando a sustentabilidade cultural da comunidade Kaingang (Paraná), com ações realizadas pelo Designer para sintetizar as etapas e recursos para a estruturação do sistema proposto.

A autora comenta que os estudos do Etnodesign (etnia + design) no Brasil podem permitir essa revitalização de saberes e tecnologias ajudando o designer a se desprender de padrões internacionalizados e focar na diversidade cultural brasileira. Afirma que as contribuições do designer ajudam a melhorar a qualidade do objeto e a percepção dessa qualidade pelo consumidor, reduzir o uso da matéria prima, aperfeiçoar os processos de fabricação, deslocar 
objetos de um segmento para outro mais valorizado no mercado, intermediar a comunicação entre as comunidades e o mercado, comunicar os atributos intangíveis do artefato e facilitar o acesso dos artesãos ou de seus artefatos à mídia. A pesquisa revelou a preocupação constante sobre a perda cultural, a carência de materiais informativos e a necessidade de desenvolver formas de preservação e valorização desses conhecimentos indígenas dentro e fora das aldeias (CAVALCANTE, 2014).

Mazza, Ipiranga e Freitas (2007), com o objetivo de apresentar exemplos de aplicação do repertório semântico do artesanato brasileiro enquanto forma de construção de identidade para os produtos nacionais, usou uma abordagem visual, por meio da observação e leitura de imagens fotográficas. Observaram que há uma preocupação em manter as características originais do artesanato (materiais, processos, técnicas) no desenvolvimento de produtos, sendo o designer quem deve interpretar os requerimentos simbólicos, práticos e técnicos da comunidade de artesãos.

Martins (2011), por meio da sua pesquisa etnográfica e participativa, descreve, analisa e aumenta o valor da tradição de cestas indígenas, ajudando a fomentar a produção dentro dos limites sustentáveis, gerando renda para os produtores indígenas. Comenta sobre a necessidade de conhecer e entender os valores, comportamentos e práticas locais de um grupo ou sociedade com o auxílio da abordagem etnográfica, que ajuda a fundamentar a análise das práticas de produção e comercialização das comunidades indígenas.

Nogueira (2005), em seu estudo de caso sobre os grafismos das cestarias do Mbya Guarani (Rio de Janeiro), utilizou o método etnográfico com o objetivo de propor o Etnodesign (etnia + design) como uma alternativa de pesquisa dentro do design, para investigações de cultura material de outras etnias. Apontou que a arte indígena tem sido estudada sistematicamente, principalmente em questões que tangem às representações gráficas; e que nos cursos de design não havia referências às manifestações plásticas indígenas.

Nogueira (2005) ainda afirma que, diante do quadro de relações entre o design e questões étnicas, o Etnodesign permite que o designer compreenda o universo visual de outras culturas, contribuindo para a constituição do imaginário do que é ser brasileiro; e ao mesmo tempo, usa conhecimento gerado por essa prática para aperfeiçoar o ensino e o desenvolvimento de produtos ou serviços.

A partir da análise desses autores (NUNES, 2013; RODRIGUES, 2006; CAVALCANTE, 2014; MAZZA; IPIRANGA; FREITAS, 2007; MARTINS, 2011; NOGUEIRA, 2005), percebe-se que pesquisas qualitativas são atreladas ao método etnográfico em conjunto com observações participantes, entrevistas, 
gravações e imagens. E que existe a necessidade de propagar o artesanato indígena brasileiro tanto para fomentar sua economia quanto para divulgar a sua cultura.

\subsection{Resultados da Revisão Bibliográfica Assistemática}

\subsubsection{Design de serviços}

Segundo Costa Júnior (2012), a disciplina Design de Serviços surgiu em 1990, e no geral, é um processo de desenvolvimento que integra vários campos de conhecimento, os quais fornecem ferramentas e técnicas. Blomkvist (2011) comenta que essa área surgiu a partir da demanda de produtos mais conscientes que auxiliassem na produção de um design mais orgânico e Vezzoli (2010) afirma que o Design de Serviços no campo da Sustentabilidade e Inovação, possibilita que implantação de princípios de equidade social, econômica e ambiental. Afirmando ainda que, o Sistema Produto+Serviço (PSS) é englobado nesta área do "design para sustentabilidade" e consegue atender às necessidades e desejos dos stakeholders de forma inovadora e estratégica.

Goedkoop et al. (1999, p. 18) definiu que Sistema Produto+Serviço (PSS) é um conjunto de produtos e serviços que são comercializáveis e capazes de satisfazer as necessidades de todos os stakeholders, e esse conjunto é nomeado sistema, que pode gerar baixo impacto ambiental. Para a UNEP (2002), o PSS é uma estratégia de inovação que muda o centro do negócio de design da venda física com o objetivo de oferecer soluções sustentáveis e reorientar as práticas de produção e consumo de forma desmaterializada. Podendo criar, assim, maior valor a partir do consumo de materiais, reduzindo o impacto ambiental significativamente no ciclo de vida de sistemas mais tradicionais. E Tukker (2003) aponta que o PSS possui 03 categorias distintas, o Sistema Produto+Serviço orientado ao Produto, o Sistema Produto+Serviço orientado ao uso e o Sistema Produto+Serviço orientado ao Resultado.

\subsubsection{Design, cultura e identidade}

A natureza multidisciplinar do Design faz com que este se molde aos aspectos mercadológicos, ambientais, tecnológicos e sociais. Segundo Santos (2005), o designer media as relações sociais do ponto de vista comunicativo e funcional, embutindo no artefato valores e tecnologias referentes ao tempo e espaço que são produzidos, sendo considerados então, produtos culturais. Assim, o Design faz parte da cultura e história de qualquer lugar (QUELUZ, 2008). 
Santos (2005) comenta que pensar as relações sócio-culturais desses artefatos produzidos pelo designer, ajuda a entender os seus significados, que podem ser alterados com o decorrer do tempo, pois por meio da produção, os seres humanos materializam suas práticas sociais e valores culturais correspondentes ao período histórico que estão vivendo, fazendo com que esses artefatos não sejam neutros. Assim, ao comprar/usar/consumir um artefato, é necessário pensar em qual contexto social, cultural e histórico a sua identidade fora construída, deixando de lado pensamentos apenas mercantilistas.

Para Ono (2006), a importância do designer na construção da cultura material se dá à medida que esse profissional compreende o significado dos artefatos, atuando como um mediador entre o produtor e o consumidor, ajudando na construção do imaginário e no desenvolvimento de boas práticas que auxiliem na tradução das necessidades dos stakeholders, ou seja, o significado de cada artefato produzido depende de uma rede de relações que se estabelecem no âmbito social dos indivíduos que o produziram.

A aproximação do design a esse universo de produção cultural de artefatos, segundo Mendes e Queluz (2005), ajuda na associação do fator econômico e cultural que resgata o trabalho artesanal como uma totalidade inserida nas práticas sociais, emancipando as comunidades artesãs por meio da valorização da sua identidade e dos seus significados, adequação dos seus processos e maior qualidade nos seus produtos. De acordo com Nascimento, Muniz e Queluz (2008), essa interação entre designers e artesãos gera vantagens para ambas as partes contribuindo para o advento de uma nova cultura nos quais os valores culturais, sociais e ambientais sejam preservados.

Para Ono (2006), a discussão sobre cultura e identidade é fundamental para o entendimento do papel do design na produção do artesanato, pois um ato de consumo é "essencialmente cultural" (BARBOSA; CAMPBELL, 2006). Entende-se cultura como uma teia de significados tecida por pessoas inseridas na sociedade, na qual desenvolvem seus pensamentos, valores e ações de acordo com seus conhecimentos, crenças, arte, moral, lei ou costumes adquiridos enquanto membro da sociedade (QUELUZ, 2008; ONO, 2006). Segundo Barbosa e Campbell (2006), perceber que produtos e serviços podem possuir materialidades distintas, torna-os tangíveis. Assim, a cultura, como processo social de produção, compõe com a economia de forma indissolúvel, não sendo, portanto, possível analisa-la isoladamente, por estar inserida em um contexto socioeconômico e vinculada a uma prática que ajuda a compreender ou transformar o sistema social (ONO, 2006).

Nesse contexto, todo o trabalho envolvido na produção de artefatos, segundo Marquesan (2013), representa uma forma potencial de consumo e suas consequências nos âmbitos econômico, social e ambiental. A desmaterialização do consumo por meio de serviços pode entrar então, como um aliado à produção artesanal como forma de fomentar a economia desses povos tradicionais. 


\subsection{3 Índios guarani MBYA}

Segundo Conrade (2015), Guaranis são da matriz cultural Tupi e são divididos em três grupos linguísticos (Mbya, Nhandeva e Kaiowá), no Brasil existem por volta de 50 mil indivíduos distribuídos nos estados do Rio Grande do Sul, Santa Catarina, Paraná, São Paulo, Espírito Santo, Rio de Janeiro, Mato Grosso do Sul, Tocantins e Pará e nesse artigo será apresentado um pouco sobre os Guarani-Mbya. Nogueira (2005) aponta que a fixação das aldeias Mbya no litoral é uma característica própria da nação Guarani que busca terras pouco habitadas e que o seu artesanato é produzido não somente para questões funcionais, mas também traz uma característica de narração cultural onde simples adornos e cestos contam histórias, mitos e tradições. Segundo Rodrigues (2006), os objetos dos índios Mbya guardam um valor que transita entre a beleza e o sentido, e são formas sensíveis que expressão sua estrutura social, relação com a natureza e construção de identidade de cada artesão.

Daniel Conrade (2015) em seu livro, conta sua experiência com os Guarani Mbya do litoral do Paraná e descreve que as expressões indígenas provém diretamente da sua vida diária e cotidiana e eles produzem objetos voltados para a perfeição formal, cujo desempenho ou simples apreciação lhes dá gozo, orgulho e alegria. Ainda afirma que essas comunidades estão passando por um período de transição negativo e que a tecnologia pode se transformar em uma ferramenta favorável para preservação dessa cultura tradicional.

\subsubsection{Benchmarking}

Neste artigo, foram analisados cinco cases para compreender a relação entre serviço dedicado à cultura indígena.

Chill out with the Sámi people é um programa de turismo que visa proporcionar uma imersão na cultura sami (índios da Finlândia) da região da Lapónia - Finlândia. Com atividades de caça, oficinas de artesanato e horários de visitas em parques, o turista vive a experiência de ser Sami por um período de tempo. Esta é uma experiência de imersão cultural e também oferece pacotes de fins de semana, feriados e eventos (VISIT FILAND, 2017?).

AIANTA é uma associação sem fins lucrativos criada por indígenas, desde 1999, que tem a missão de definir, apresentar, crescer e sustentar o turismo havaiano nativo, do Alasca e da América do Norte, honrando suas tradições e valores. AIANTA auxilia essas comunidades tradicionais na criação de infraestrutura, fornecendo-Ihes assistência técnica, treinamento e recursos educacionais, com o objetivo de melhorar seus serviços já existentes (AIANTA, 2017). 
A Terra de Arnhem se localiza no norte da Austrália, os Yolngu ocupam a região há pelo menos 60 mil anos. Na reserva, existem 11 mil indígenas como residentes permanentes e proprietários de terras por lei de sucessão (HEALY, 2004). Para os turistas que visitam a Austrália, há lojas de souvenirs contendo utensílios indígenas, instrumentos musicais e arte figurativa, representados por cores pintadas de preto, amarelo, branco e vermelho (TOURISM AUSTRALIA, 2017). Outras formas de exportar sua cultura é por meio de recursos audiovisuais, para educar os descendentes indígenas que vivem em regiões urbanas e turistas; E algumas imagens transmitidas, são informativas sobre simbologia e lugares místicos (FREY, 2017).

O Turismo Indígena de Ontário, no Canadá, proporciona por meio de empresas criadas pela comunidade local, passeios culturais aos turistas em territórios aborígenas (como são denominados os indígenas canadenses) além da realização de workshops educacionais sobre lendas e cultura enquanto ensinam a fazer $\mathrm{o}$ artesanato local.

II Ngwesi se localiza na África e é administrado pela comunidade Maasai no Quênia, que proporciona aos turistas uma experiência cultural na vida selvagem e com instalações em casas dos nativos. Além disso, oferecem projetos comunitários onde é permitido passar um período de tempo com as mulheres locais para aprender sobre as técnicas de artesanato ou visitar escolas/clínicas para conhecer e se tornar um doador (IL NGWESI, 2017).

Na Figura 2, há as atividades proporcionadas por estes cinco cases comentados acima.

O Benchmarking mostrou que proporcionar a imersão da cultura e fomentar o turismo local, preservando o fazer tradicional dos povos indígenas proporciona, de forma eficaz, a desmaterialização do consumo por meio de serviços que gera trabalho e renda positiva, que permite que esses povos consigam, segundo Marquesan (2013), ir além da sobrevivência de grupos ou comunidades.

\section{DISCUSSÃO}

A relação entre Design e Artesanato foi bastante citada de acordo com os princípios de Papanek (1995), que afirma que o design "deve ser a ponte entre as necessidades humanas, a cultura e a ecologia" (PAPANEK, 1995 apud RIUL, 2015, p. 47) gerando soluções aplicáveis a problemas do mundo real. Rodrigues (2006) declara que o indígena não é um agente passivo no processo e que o papel do designer é encontrar o diálogo que traduz a cultura, por meio das expressões indígenas, para preparar o mercado para aprender, aceitar e valorizar os seus objetos culturais. A intervenção de projeto só acontece quando compreende os aspectos intangíveis e cognitivos dessas comunidades nativas e prioriza as formas simbólicas do território. 
Figura 2 - Atividades dos serviços encontrados no Benchmarking.

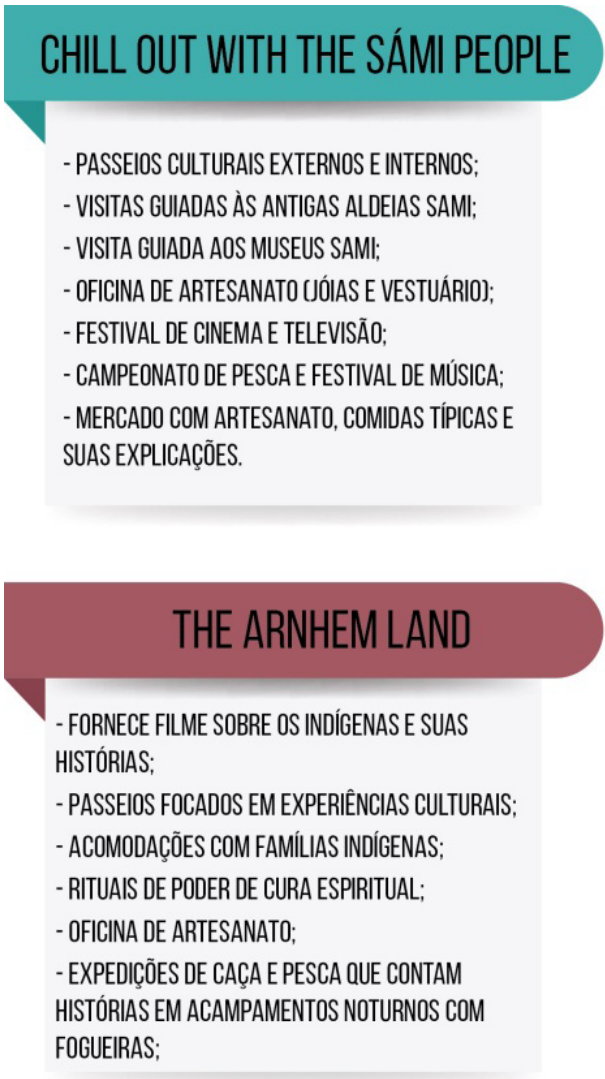
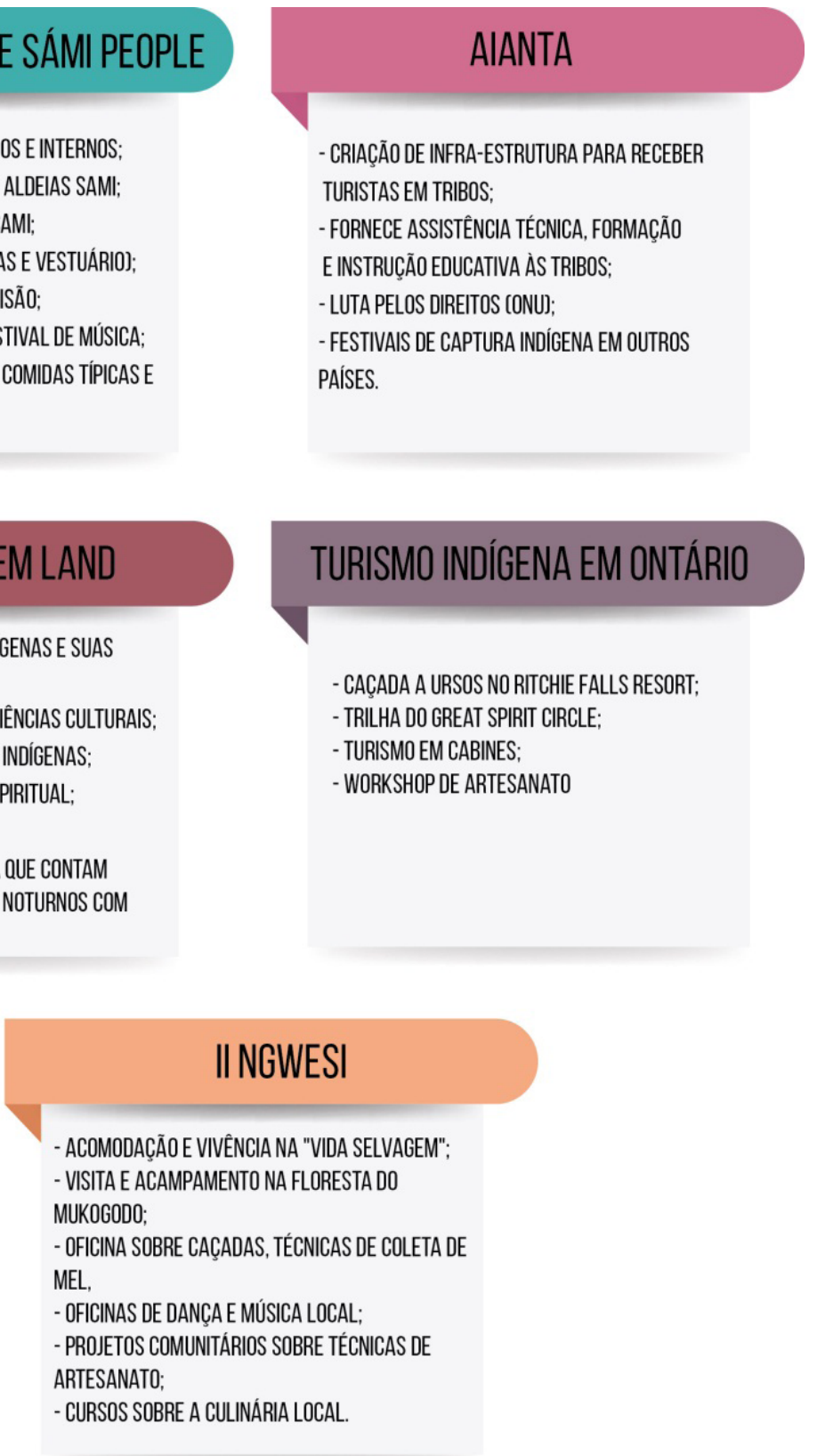

Fonte: Autores (2018).

Cavalcante (2014) aponta como resultado da sua pesquisa, a necessidade de revitalização do conhecimento indígena, a valorização da identidade étnica e a produção de artefatos englobados com a disseminação do conhecimento indígena. Há uma preocupação em relação às perdas culturais que envolvem as tradições, as histórias, as técnicas e o modo de fazer assim como o desejo do povo indígena de ter uma maior comunicação com o Juruá (homem branco) que ajude no compartilhamento de conhecimentos, traçando uma mão dupla de valorização e fortalecimento cultural. Ainda ressalta que trabalhar no contexto indígena exige que o designer tenha a disposição de assimilar a subjetividade e a intersubjetividade dos artesãos e que aprenda a desempenhar as suas ações no tempo e espaço dessas comunidades. 
De acordo com Marquesan (2013), a prática do artesanato indígena no interior do sistema capitalista para fortalecer a sua cultura e manter o seu modo de vida se torna um elemento fundamental para a sobrevivência da sua identidade sem garantir a sua preservação. Ono (2006), aborda que - Designer ajuda a mediar essa prática na criação visando modificar esse sistema mercantilista já estabelecido na sociedade. Concluindo assim que essa associação do fator econômico com o cultural que Mendes e Queluz (2005) retratam, pode ocorrer de forma distintas e ajudar na desmaterialização do consumo por meio de serviços.

De um modo geral, a RBS apresentada reforça a lacuna entre o Design e o fazer tradicional, focando, quase sempre, apenas no artefato físico. Se consumo da produção indígena é algo essencialmente cultural (BARBOSA; CAMPBELL, 2006), a necessidade revelada no presente estudo encontra-se em como desmaterializar a produção cultural dos fazeres tradicionais para que seus consumidores experienciem a cultura em sua totalidade?

Para os autores (BARBOSA; CAMPBELL, 2006) perceber que esses artefatos físicos podem assumir materialidades distintas por meio de serviços, torna social o processo de produção social, envolvendo a co-criação da experiência cultural do fazer tradicional.

\section{CONSIDERAC̣ÕES FINAIS}

Para analisar a contribuição do Design no Artesanato Indígena Brasileiro, esse artigo apresentou um estudo para compreender a relação e problemática envolvida no campo Design versus Artesanato Indígena. Como apontado, existem trabalhos envolvendo design e artesanato indígena no Brasil entre os anos de 2003 e 2015, porém grande parte dos autores encontrados na Revisão Bibliográfica Sistemática e Assistemática apontam lacunas nessa relação e criticam algumas ações de designers na interferência da cultura local.

A partir da pesquisa da literatura qualificada pode-se perceber que as relações que o Design estabelece com a sociedade e sua cultura aumenta o conhecimento das tradições locais por meio do reconhecimento do valor da identidade cultural do artesanato. Tornando o designer um agente integrador que desenvolve produtos e/ou serviços com valores comerciais agregados que possuem os valores culturais intrínsecos. Além disso, foi apresentada a necessidade do designer em se posicionar de forma consciente, criativa e sem estereótipos diante das riquezas culturais; e de assumir responsabilidades de tornar seus produtos e serviços mais adaptados ao mercado, sem intervir no fazer tradicional e se preocupando, ao mesmo tempo, com a dimensão social, ambiental e econômica. 
Assim, as revisões bibliográficas apresentadas nesse artigo mostraram que é possível acontecer a interação entre design e artesanato se houver a cooperação mútua entre todas as partes. Mas é necessário que o meio acadêmico se torne mais participativo e sensível para as demandas dos grupos mais necessitados e menos assistidos. Nascimento, Muniz e Queluz (2008), afirmam que é real a possibilidade do design contribuir para a melhoria de produtos e processos, permitindo a inserção desses produtos artesanais de forma desmaterializada no mercado e melhorando a qualidade de vida desses artesãos.

\section{REFERÊNCIAS}

AIANTA - AMERICAN INDIAN ALASKA NATIVE TOURISM ASSOCIATION. About us. In: AIANTA. Albuquerque: AINTA, 2017. Disponível em: https:// www.aianta.org/about-us/. Acesso em: 12 jul. 2017.

BARBOSA, Lívia; CAMPBELL, Colin. Cultura, consumo e identidade. Rio de Janeiro: FGV, 2006.

BLOMKVIST, Johan. Conceptualising prototypes in service design. 2011. 149 f. Tese (Doutorado em Computação e Ciência da Informação) - Linköping University, Linköping, 2011.

CARNEIRO FILHO, Arnaldo; SOUZA, Oswaldo Braga de. Atlas de pressões e ameaças às terras indígenas na Amazônia brasileira. São Paulo: Instituto Socioambiental, 2009.

CAVALCANTE, Ana Luisa Boavista Lustosa. Design para a sustentabilidade cultural: recursos estruturantes para sistema habilitante de revitalização de conhecimento local e indígena. 2014. $321 \mathrm{f}$. Tese (Doutorado em Engenharia e Gestão de Conhecimento) - Universidade Federal de Santa Catarina, Florianópolis, 2014.

CONFORTO, Edivandro Carlos; AMARAL, Daniel Capaldo; SILVA, Sérgio Luis da. Roteiro para revisão bibliográfica sistemática: aplicação no desenvolvimento de produtos e gerenciamento de projetos. In: CONGRESSO BRASILEIRO DE GESTÃO DE DESENVOLVIMENTO DE PRODUTO, 8., 2011, Porto Alegre. Anais [...]. Porto Alegre: IGDP, 2011. p. 1-12.

CONRADE, Daniel. A arte Guarani-Mbya de Guaraqueçaba, aldeia Kuaray Guata Porã. Curitiba: Edição do autor, 2015.

COSTA JÚNIOR, Jairo da; SANTOS, A. DOS. Proposição de um modelo de referência para o design de serviços eco eficientes em sistemas produtoserviço. Dissertação (Mestrado em Design) - Universidade Federal do Paraná, Curitiba, 2012.

FREY, Aline. Ativismo coletivo e descolonização midiática: uma análise comparativa das produções audiovisuais indígenas na Austrália e no Brasil. Revista Tempos e Espaços em Educação, São Cristóvão, v. 10, n. 21, p. 41-54, jan./abr. 2017. Disponível em: https://seer.ufs.br/index.php/revtee/article/ view/6331/5253. Acesso em: 10 maio 2017. 
GOEDKOOP, Mark Jacob; VAN HALEN, Cees J. G.; TE RIELE, Harry R. M.; ROMMENS, Peter J. M. Product service systems: ecological and economic basics. Rotterdam: Storrm CS, 1999.

HEALY, J. Do trabalho de campo ao arquivo digital: performance, interação e Terra de Arnhem, Austrália. Horizontes Antropológicos, Porto Alegre, v. 10, n. 21, p. 67-95, jan./jun. 2004. Disponível em: http://www.scielo.br/pdf/ha/ v10n21/20620.pdf. Acesso em: 10 maio 2017.

IL NGWESI. People of Wildlife. 2017. Disponível em: http://ilngwesi.com/ content/visit/. Acesso em: 12 jul. 2017

KRUCKEN, Lia. Design e território: valorização de identidades e produtos. São Paulo: Studio Nobel, 2009

MARQUESAN, Fábio Freitas Schilling. Terra e artesanato Mbyá-Guarani: polos da contraditória política indigenista no Rio Grande do Sul. 2013. 142 f. Tese (Doutorado em Administração) - Universidade Federal do Rio Grande do Sul, Porto Alegre, 2013.

MARSALIA NETO, Luiz; MACEDO, Mariana de Oliveira; RODRIGUES, Rodrigo da Silva; CARVALHO, Weuller de; DUTRA, Karen Estefan. Benchmarking: um instrumento para o mundo moderno. Revista Eletrônica da Faculdade Metodista Granbery, Juiz de Fora, n. 5, jul./dez. 2008.

MARTINS, Rafael D'Almeida. Fair trade practices in the Northwest Brazilian Amazon. BAR: Brazilian Administration Review, Curitiba, v. 8, n. 4, p. 412-432, Oct./Dec. 2011.

MAZZA, Adriana Carla Avelino; IPIRANGA, Ana Sílvia Rocha; FREITAS, Ana Augusta Ferreira de. O design, a arte e o artesanato deslocando o centro. Cadernos EBAPE.BR, Rio de Janeiro, v. 5, n. 4, dez. 2007

MENDES, Mariuze Dunajski; QUELUZ, Gilson Leandro. Design e artesanato: reflexões sobre uma abordagem não reitificadora nas pesquisas e interações com as comunidades. In: QUELUZ, Marilda Lopes Pinheiro (org.). Design \& cultura. Curitiba: Editora Sol, 2005. p. 57-82.

NASCIMENTO, Marilzete Basso do; MUNIZ, Graciela Inez Bolzon de; QUELUZ, Gilson Leandro. Interação entre design e artesanato: uma experiência em Rio Rufino - SC. In: QUELUZ, Marilda Lopes Pinheiro (org.). Design \& identidade. Curitiba: Editora Peregrina, 2008. p. 81-103.

NOGUEIRA, José Francisco Sarmento. Etnodesign: um estudo do grafismo das cestarias dos M'byá Guarani de Paraty-Mirim (RJ). 2005. 135 f. Dissertação (Mestrado em Artes e Design) - Pontifícia Universidade Católica do Rio de Janeiro, Rio de Janeiro, 2005.

NORONHA, Raquel Gomes. Era uma vez no quilombo: narrativas sobre turismo, autenticidade e tradição entre artesãs de Alcântara (MA). Textos Escolhidos de Cultura e Arte Populares, Rio de Janeiro, v. 12, n. 1, p. 43-60, maio 2015.

NUNES, Lília Tereza Diniz. Design e cultura: um olhar sobre o artesanato de Capim Dourado. 2013. 136 f. Dissertação (Mestrado em Design) Universidade Anhembi Morumbi, São Paulo, 2013. 
ONO, Maristela Mitsuko. Design e cultura: sintonia essencial. Curitiba: Edição da autora, 2006.

PAPANEK, Victor. Design for the real world: human ecology and social change. 2nd. London: Thames \& Hudson, 1995.

QUELUZ, Marilda Lopes Pinheiro. Questões pontuais sobre design e identidade. In: QUELUZ, Marilda Lopes Pinheiro (org.). Design \& identidade. Curitiba: Editora Peregrina, 2008. p. 13-33.

RIUL, Marília. Pegar e fazer: a dinâmica da produção e dos usos de artefatos artesanais na região da Barra do Rio Mamanguape - PB e reflexões sobre design e produção do mundo artificial. 2015. 299 f. Tese (Doutorado em Ciência Ambiental) - Universidade de São Paulo, São Paulo, 2015.

RODRIGUES, Taisa Figueira. Um olhar do design sobre a iconografia indígena: a ornamentação corporal kayapó: um estudo de caso. 2006. 104 f. Dissertação (Mestrado em Artes e Design) - Pontifícia Universidade Católica do Rio de Janeiro, Rio de Janeiro, 2006.

SANTOS, Marinês Ribeiro dos. Design e cultura: os artefatos como mediadores de valores e práticas sociais. In: QUELUZ, Marilda Lopes Pinheiro (org.). Design \& cultura. Curitiba: Editora Sol, 2005. p. 13-32.

TOURISM AUSTRALIA. Aboriginal experiences. Disponível em: http://www. tourism.australia.com/aboriginal/aboriginal-experiences.aspx. Acesso em: 12 jul. 2017.

TUKKER, Arnold. Eight types of product-service systems: eight ways to sustainability? Experiences from SusProNet. In: INTERNATIONAL CONFERENCE OF THE GREENING OF INDUSTR.Y NETWORK, 11., 2003, San Francisco. Proceedings [...]. Enschede: GIN, 2003. CD-ROM.

UNEP - UNITED NATIONS DEVELOPMENT PROGRAMME. Product-service systems and sustainability: opportunities for sustainable solutions. Genebra: INDACO - Department Politecnico di Milano., 2002.

VEZZOLI, C. Design de sistemas para a sustentabilidade. Salvador: EDUFA, 2010.

VISIT FILAND. Chill out with the Sámi people. 2017. Disponível em: http:// www.visitfinland.com/article/chill-out-with-the-sami-people/. Acesso em: 12 jul. 2017. 